\title{
Improved Non-Covalent Biofunctionalization of Multi-Walled Carbon Nanotubes Using Carbohydrate Amphiphiles with a Butterfly-Like Polyaromatic Tail
}

\author{
Mohyeddin Assali ${ }^{1}$, Manuel Pernía Leal ${ }^{1}$, Inmaculada Fernández ${ }^{2}$, Pablo Romero-Gomez ${ }^{3}$, Rachid Baati ${ }^{4}$, and \\ Noureddine $\operatorname{Khiar}^{1}(\bowtie)$ \\ ${ }^{1}$ Instituto de Investigaciones Químicas, C.S.I.C-Universidad de Sevilla, c/. Américo Vespucio, 49, Isla de la Cartuja, Sevilla 41092, Spain \\ ${ }^{2}$ Departamento de Química Orgánica y Farmacéutica, Facultad de Farmacia, Universidad de Sevilla, Sevilla 41012, Spain \\ ${ }^{3}$ Instituto de Ciencias de Materiales de Sevilla, C.S.I.C-Universidad de Sevilla, c/. Américo Vespucio, 49, Isla de la Cartuja, Sevilla 41092, \\ Spain \\ ${ }^{4}$ Université de Strasbourg Faculté de Pharmacie CNRS/UMR 7199, Laboratoire des Systèmes Chimiques Fonctionnels BP 60024,74 route \\ du Rhin, 67400 Illkirch, France
}

Received: 27 July 2010 / Revised: 9 September 2010 / Accepted: 9 September 2010

(C) The Author(s) 2010. This article is published with open access at Springerlink.com

\begin{abstract}
We have developed an efficient strategy for the non-covalent functionalization of multi-walled carbon nanotubes (MWCNTs) which allows a biomimetic presentation of carbohydrates on their surface by $\pi-\pi$ stacking interactions. The strategy is based on the use of sugar-based amphiphiles functionalized with tetrabenzo[a,c,g,i]fluorene (Tbf), a polyaromatic compound with a topology that resembles a butterfly with open wings. The new carbohydrate-tethered Tbf amphiphiles have been synthesized in a straightforward manner using click chemistry. The reported method has been developed in order to improve the rather low ability of pyrene-based systems to exfoliate MWCNTs in water. By means of thermogravimetric analysis (TGA), ultraviolet (UV), infrared (IR), and fluorescence spectroscopies the interaction between MWCNTs and the Tbf group has been found to be stronger than those involving pyrene-based amphiphilic carbohydrates. The resulting aggregates with a multivalent sugar exposition on their surface are able to engage in specific ligand-lectin interactions similar to glycoconjugates on a cell membrane.
\end{abstract}

\section{KEYWORDS}

Carbon nanotubes, non-covalent functionalization, tetrabenzo $[a, c, g, i]$ fluorene, carbohydrates, click chemistry, biocompatible system

\section{Introduction}

Since their discovery in 1991 [1], carbon nanotubes (CNTs) have received an unrivalled interest as a consequence of their unique structural, mechanical, electrical, and optical properties [2,3]. To date, CNTs

Address correspondence to khiar@iiq.csic.es are being actively investigated for a wide range of biomedical applications [4,5], including biosensing [6], imaging [7-9], drug delivery [10-16], and specific targeting and killing of cancer cells [17-19]. However, these and other potential biomedical applications have been hampered by the insolubility of CNTs in 
most solvents, most importantly in water where they exist as ropes and large bundles. To overcome the drawbacks of insolubility and poor dispersibility, surface functionalization of the CNT sidewalls has emerged as a powerful and viable strategy to exfoliate CNTs, resulting in the preparation of stable aqueous/ organic suspensions with moderate to low cytotoxicity [20-22]. Such surface modification allows CNTs to engage in specific binding events with various biological systems [23]. So far many strategies have been developed to exfoliate CNTs into solution, including covalent and non-covalent functionalization [24-26]. The non-covalent approach is more desirable as it conserves the nanotube structure, while the covalent approach has been shown to disrupt their $\pi$-network, leading to possible loss of their mechanical, electrical, and biosensing properties. Following the pioneering work of Dai et al. [27], the supramolecular non-covalent $\pi-\pi$ stacking strategy has shown itself to be an efficient way to introduce a large number of functionalities onto the surface of carbon nanotubes [28-31], and has been recently used to load polyaromatic chemotherapy agents directly onto the surface $[32,33]$. Yet, despite the significant advances achieved, the attachment of functional aromatic scaffolds onto the nanotube surface generally depends on the use of pyrene (Py) as the anchor [34]. Taking into account the large heterogeneity of the surface curvature and diameter of carbon nanotubes, the pyrene moiety with its specific size and shape is far from being a general anchor for all kind of nanotubes [35]. Thus, the design of a new aromatic anchor, ideally complementary to pyrene, to non-covalently tailor the surface of CNTs is highly desirable.

On the other hand, recent investigations have confirmed the prime role of carbohydrates in critical biological events, including cell adhesion, inflammation, tumour cell metastasis, and pathogen infections [36-38]. Interestingly, it has been demonstrated that the weak interaction between an individual ligand and the corresponding specific lectin is compensated by multivalent presentation (display) of carbohydrates through the so called cluster effect [39, 40]. Thus, biocompatible model systems able to display a large number of glycoligands on their surface are of interest in glycobiology to study carbohydrate functions and to interfere with native binding events. Consequently, owing to their high aspect ratio and surface areawhich enable the display of a large number of carbohydrate motifs-and to their semi flexible nature-which facilitates their binding to specific receptors-CNTs constitute an ideal molecular platform for the multivalent display of carbohydrates [41, 42].

Following our interest in the utilization of CNTs as a molecular jig for the preparation of sugar-based bionanomaterials $[43,44]$, and in order to improve the rather low ability of pyrene-based systems to exfoliate multi-walled carbon nanotubes (MWCNTs) in water [45], herein we report the synthesis and use of new carbohydrates-based amphiphiles I with a polyaromatic tetrabenzo[ $[a, c, g, i]$ fluorene (Tbf) tail, designed to optimize the $\pi-\pi$ interactions with the sidewalls of MWCNTs. This work has resulted in the development of an efficient strategy for the functionalization of MWCNTs, which allows the synthesis of novel robust water soluble nanoglycoarrays with a biomimetic presentation of carbohydrates on their surface (Scheme 1).

\section{Experimental}

\subsection{General methods}

All reactions were performed under an atmosphere of dry argon using oven-dried glassware and freshly distilled and dried solvents. Tetrahydrofuran (THF) and diethyl ether were distilled from sodium benzophenone ketyl. $\mathrm{CH}_{2} \mathrm{Cl}_{2}$ was distilled from calcium hydride. Thin layer chromatography (TLC) was performed on silica gel GF254 (Merck) with detection by charring with phosphomolybdic acid/EtOH and sulphuric acid/EtOH. Reagents were obtained from commercial suppliers and used without further purification. For flash chromatography, silica gel (Merck 230-400 mesh) was used. The organic extracts were dried over anhydrous sodium sulfate and concentrated under vacuum. Columns were eluted with positive air pressure. Chromatographic eluents are given as volume to volume ratios $(v / v)$. Nuclear magnetic resonance (NMR) spectra were recorded with a Bruker AMX500 $\left({ }^{1} \mathrm{H}\right.$, $500 \mathrm{MHz})$ and Bruker Avance DRX500 $\left({ }^{1} \mathrm{H}, 500 \mathrm{MHz}\right)$ 


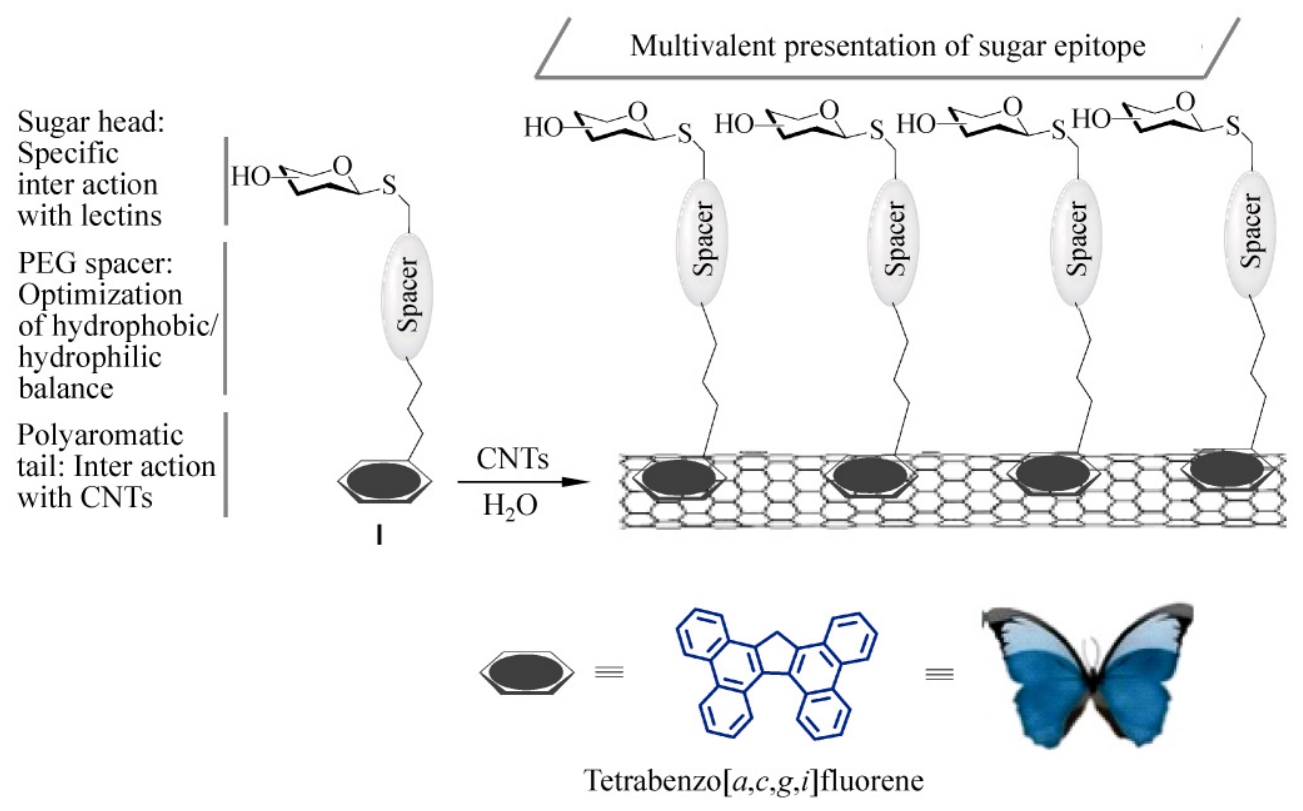

Scheme 1 Schematic representation of the synthesis of the Tbf-linked carbohydrate-MWCNTs nanoglycoarrays used in this work

spectrometers. Chemical shifts are reported in ppm, and coupling constants are reported in Hz. Routine spectra were referenced to the residual proton or carbon signals of the solvent. High-resolution mass spectra (HRMS) were recorded on a Kratos MS-80RFA 241-MC apparatus. Optical rotations were determined with a PerkinElmer 341 polarimeter. Transmission electron microscopy (TEM) images of glycolipid-coated CNTs were obtained on a Philips CM-200 microscope operating at an electron energy of $200 \mathrm{keV}$ and magnification of 10,000-300,000 times. Samples were prepared by depositing $15 \mu \mathrm{L}$ of a suspension onto grids and allowing the grids to absorb the material for $2 \mathrm{~min}$. Scanning electron microscope (SEM) images of glycolipid-coated CNTs were obtained on a JEOL JSM-5400 microscope with a magnification of 15,000 times. Samples were prepared by depositing $15 \mu \mathrm{L}$ of a suspension onto grids and allowing the grids to absorb the material for $2 \mathrm{~min}$. Infrared (IR) spectra were obtained with a Bruker Vector 22 spectrometer as $\mathrm{KBr}$ disks. Ultraviolet-visible (UV-vis) spectra were obtained with a PerkinElmer Lambda 12 spectrometer. Raman spectra were recorded on a LabRAM HR800 high resolution UV confocal Raman microscope using a green laser (He-Ne $532.14 \mathrm{~nm}), 600$ line/mm, 20X objective, $20 \mathrm{~mW}$, pinhole $100 \mu \mathrm{m}$. Thermogravimetric analysis (TGA) was carried out with a TA instruments
TGA Q600 thermal analyzer in the temperature range 0-600 ${ }^{\circ} \mathrm{C}$, with a heating rate of $20{ }^{\circ} \mathrm{C} / \mathrm{min}$ rate, under $\mathrm{N}_{2}(100 \mathrm{~mL} / \mathrm{min})$. Fluorescence measurements were performed using a HORIBA Jobin Yvon Fluorolog FL3-11 fluorimeter equipped with two monochromators (excitation wavelength $345 \mathrm{~nm}$ ). MWCNTs (Aldrich) were produced by chemical vapor deposition (external diameter 10-15 nm; internal diameter 2-6 nm; length $0.1-10 \mu \mathrm{m}$ ) and were used as received.

\subsection{Synthesis}

Flow charts of the synthesis process are shown in Schemes 2 and 3.

\section{Synthesis of 17-(prop-2-yn-1-yl)-tetrabenzo[a,c,g,i] fluorene (5)}

To 8bH-tetrabenzo[ $[a, c, g, i]$ fluorene $(4)(1 \mathrm{~g}, 2.73 \mathrm{mmol})$, in degassed dioxane $(50 \mathrm{~mL})$ heated at reflux, was added tetrabutylammonium hydroxide $(40 \% \mathrm{w} / \mathrm{w}$ in $\mathrm{H}_{2} \mathrm{O}, 644 \mathrm{mg}, 2.48 \mathrm{mmol}$ ) as a solution in degassed dioxane $(10 \mathrm{~mL})$, resulting in the immediate formation of a yellow precipitate. This was filtered under $\mathrm{N}_{2}$ and washed with warm dioxane $(100 \mathrm{~mL})$ and ether $(100 \mathrm{~mL})$. The salt was resuspended in dioxane $(100 \mathrm{~mL})$, treated with propargyl bromide $(214 \mu \mathrm{L}$, $2.48 \mathrm{mmol}$ ), and the mixture heated to reflux for $2 \mathrm{~h}$. The solvent was removed from the darkened solution, 
forming a residue which was dissolved in ether $(50 \mathrm{~mL})$ and the supernatant removed to leave a yellow slurry which was washed with ether $(2 \times 30 \mathrm{~mL})$. The extract was dried $\left(\mathrm{Na}_{2} \mathrm{SO}_{4}\right)$, and the solvent removed under reduced pressure, forming a residue which was purified by silica gel chromatography using (hexane/ $\mathrm{CH}_{2} \mathrm{Cl}_{2}$ 3:1) to give $400 \mathrm{mg}$ of an amorphous yellow solid (40\% yield): $R_{\mathrm{f}}=0.44$ (hexane/ $\mathrm{CH}_{2} \mathrm{Cl}_{2} 3: 1$ ). ${ }^{1} \mathrm{H}$ NMR $\left(500 \mathrm{MHz}, \mathrm{CDCl}_{3}\right) \delta: 8.78-8.75(\mathrm{~m}, 4 \mathrm{H}), 8.67(\mathrm{~d}, J=8.2$, $2 \mathrm{H}), 8.16(\mathrm{~d}, J=7.8,2 \mathrm{H}), 7.70-7.60(\mathrm{~m}, 8 \mathrm{H}), 4.79(\mathrm{t}, J=$ $4.5,1 \mathrm{H}), 3.25-3.24(\mathrm{~m}, 2 \mathrm{H}), 1.51(\mathrm{t}, J=2.5,1 \mathrm{H}) .{ }^{13} \mathrm{C} \mathrm{NMR}$ $\left(125.7 \mathrm{MHz}, \mathrm{CDCl}_{3}\right)$ \&: 143.3, 137.1, 131.6, 130.6, 128.4, 128.0, 127.7, 127.0, 126.1, 125.9, 125.1, 124.4, 123.6, 80.2, 71.1, 53.5, 45.9, 24.4. HRMS calcd. for $\mathrm{C}_{32} \mathrm{H}_{21}[\mathrm{M}]^{+}: \mathrm{m} / \mathrm{z}$ 405.1643, found: 405.1671 .

\section{Synthesis of Tbf-PEG-Lac-8}

To a solution of the azide (6) (82 $\mathrm{mg}, 0.09 \mathrm{mmol})$ and the alkyne (5) (45 mg, $0.11 \mathrm{mmol})$ in anhydrous $\mathrm{CH}_{2} \mathrm{Cl}_{2}$ ( $5 \mathrm{~mL}$ ), were added $\mathrm{N}, \mathrm{N}$-diisopropylethylamine (DIPEA) $(48 \mu \mathrm{L}, 0.27 \mathrm{mmol})$ and copper(I) iodide $(6 \mathrm{mg}$, $0.027 \mathrm{mmol}$ ). The resulting solution was stirred under argon overnight at room temperature. After dilution with $\mathrm{CH}_{2} \mathrm{Cl}_{2}(100 \mathrm{~mL})$, washing with $1 \mathrm{~mol} / \mathrm{L} \mathrm{HCl}$ $(15 \mathrm{~mL})$, saturated aqueous $\mathrm{NaHCO}_{3}(30 \mathrm{~mL})$, and brine $(15 \mathrm{~mL})$, the organic phase was dried over $\mathrm{Na}_{2} \mathrm{SO}_{4}$ and evaporated under reduced pressure. The crude product was purified by silica gel chromatography, eluting with ethyl acetate/hexane/isopropanol (4:2:1) to give the per-acetylated Tbf-PEG-Lac-8 $(81 \mathrm{mg}$, 70\% yield) as a yellow oil: $R_{\mathrm{f}}=0.51$ (ethyl acetate/hexane/ isopropanol 4:2:1). $[\alpha]_{\mathrm{D}}=-4.0$ (c 1.0, $\left.\mathrm{CHCl}_{3}\right) .{ }^{1} \mathrm{H} \mathrm{NMR}$ $\left(500 \mathrm{MHz}, \mathrm{CDCl}_{3}\right) \delta: 8.80(\mathrm{t}, J=8.3,4 \mathrm{H}), 8.57(\mathrm{~d}, J=$ $8.3,2 \mathrm{H}), 8.23(\mathrm{~d}, J=7.3,2 \mathrm{H}), 7.74-7.68(\mathrm{~m}, 6 \mathrm{H}), 7.61(\mathrm{t}$, $J=7.7,2 \mathrm{H}), 7.09(\mathrm{t}, J=6.2,1 \mathrm{H}), 5.96(\mathrm{~s}, 1 \mathrm{H}), 5.36-5.34$ $(\mathrm{m}, 2 \mathrm{H}), 5.19(\mathrm{t}, J=9.2,1 \mathrm{H}), 5.11(\mathrm{dd}, J=10.2, J=2.2$, $1 \mathrm{H}), 4.97(\mathrm{dd}, J=10.4, J=3.4,1 \mathrm{H}), 4.91(\mathrm{t}, J=9.5,1 \mathrm{H})$, $4.49-4.47(\mathrm{~m}, 3 \mathrm{H}), 4.14-4.03(\mathrm{~m}, 4 \mathrm{H}), 3.94(\mathrm{t}, J=5.0$, $2 \mathrm{H}), 3.88-3.84(\mathrm{~m}, 5 \mathrm{H}), 3.78(\mathrm{t}, J=9.5,1 \mathrm{H}), 3.63-3.13$ (m, 12H), 2.84-2.64 (m, 2H), $2.17(\mathrm{~s}, 3 \mathrm{H}), 2.08(\mathrm{~s}, 3 \mathrm{H})$, $2.06(\mathrm{~s}, 3 \mathrm{H}), 2.05(\mathrm{~s}, 3 \mathrm{H}), 2.04(\mathrm{~s}, 3 \mathrm{H}), 2.03(\mathrm{~s}, 3 \mathrm{H}), 1.99$ (s, 3H). ${ }^{13} \mathrm{C}$ NMR $\left(125.7 \mathrm{MHz}, \mathrm{CDCl}_{3}\right) \delta: 170.3,170.2$, 170.1, 169.8, 169.6, 169.1, 143.9, 142.8, 136.7, 131.4, $130.4,128.6,128.0,127.3,127.1,126.2,125.9,125.1$, 124.9, 123.7, 123.5, 122.1, 101.1, 83.6, 76.1, 73.7, 71.0, $70.7,70.4,70.2,70.1,70.0,69.1,69.0,66.6,62.1,60.8$,
49.5, 46.9, 38.9, 31.2, 30.4, 20.8, 20.7, 20.6, 20.5. HRMS calcd. for $\mathrm{C}_{68} \mathrm{H}_{75} \mathrm{~N}_{4} \mathrm{O}_{21} \mathrm{~S}[\mathrm{M}]^{+}: \mathrm{m} / z$ 1315.4645, found: 1315.4656.

To a solution of per-acetylated Tbf-PEG-Lac-8 $(40 \mathrm{mg}$, $0.031 \mathrm{mmol})$ in dry $\mathrm{MeOH}(3 \mathrm{~mL})$ was added $\mathrm{NaOMe}$ $(1.1 \mathrm{mg}, 0.02 \mathrm{mmol})$. The reaction was allowed to proceed at room temperature for $1 \mathrm{~h}$ at which time the reaction was judged complete by TLC analysis. A sufficient quantity of Amberlyst Ir-120 (plus) $\left(\mathrm{H}^{+}\right.$form) resin was added to the mixture to render the $\mathrm{pH}$ of the solution neutral. The resin was removed by filtration and the solvent removed under vacuum. The crude product was purified by size-exclusion chromatography (Sephadex® 20), eluting with $\mathrm{MeCN} / \mathrm{H}_{2} \mathrm{O} / \mathrm{NH}_{4} \mathrm{OH}$ 6:1:1. Lyophylization of the solvent gave Tbf-PEG-Lac-8 (30 $\mathrm{mg}, 94 \%)$ as a yellowish solid: $R_{\mathrm{f}}=0.60\left(\mathrm{MeCN} / \mathrm{H}_{2} \mathrm{O} / \mathrm{NH}_{4} \mathrm{OH}\right.$ 6:1:1); $[\alpha]_{\mathrm{D}}=-7.9$ (c 1.0, MeOH). ${ }^{1} \mathrm{H}$ NMR $(500 \mathrm{MHz}, \mathrm{MeOD})$ $\delta: 8.91(\mathrm{~d}, J=8.2,4 \mathrm{H}), 8.50(\mathrm{~d}, J=8.3,2 \mathrm{H}), 8.41(\mathrm{~d}, J=$ $7.9,2 \mathrm{H}), 7.95(\mathrm{t}, J=6.5,1 \mathrm{H}), 7.83-7.71(\mathrm{~m}, 6 \mathrm{H}), 7.62(\mathrm{t}$, $J=7.7,2 \mathrm{H}), 5.95(\mathrm{~s}, 1 \mathrm{H}), 5.39(\mathrm{t}, J=4.5,1 \mathrm{H}), 4.40-4.35$ $(\mathrm{m}, 2 \mathrm{H}), 3.97-3.38(\mathrm{~m}, 24 \mathrm{H}), 3.16-3.10(\mathrm{~m}, 4 \mathrm{H}), 3.07-$ $3.03(\mathrm{~m}, 2 \mathrm{H}), 2.85-2.66(\mathrm{~m}, 2 \mathrm{H}) .{ }^{13} \mathrm{C}$ NMR $(125.7 \mathrm{MHz}$, MeOD) $\delta: 172.7,144.8,143.4,137.4,132.9,131.8,129.9$, 129.0, 128.4, 128.3, 127.6, 127.2, 126.2, 125.9, 124.9, 124.8, 123.4, 105.1, 86.9, 80.6, 80.4, 77.9, 77.1, 74.8, 74.1 72.5, 71.7, 71.4, 71.1, 71.0, 70.9, 70.3, 69.9, 62.5, 62.1, 50.6, 47.8, 40.4, 31.7, 30.7, 30.5. HRMS calcd. for $\mathrm{C}_{54} \mathrm{H}_{60} \mathrm{~N}_{4} \mathrm{O}_{14} \mathrm{SNa}$ $[\mathrm{M}+\mathrm{Na}]^{+}: \mathrm{m} / \mathrm{z}$ 1043.3724, found: 1043.3770 .

\section{Synthesis of Tbf-PEG-Man-9}

To a solution of the azide (7) $(90 \mathrm{mg}, 0.14 \mathrm{mmol})$ and the alkyne (5) (70 mg, $0.17 \mathrm{mmol}$ ) in anhydrous $\mathrm{CH}_{2} \mathrm{Cl}_{2}$ $(7 \mathrm{~mL})$, were added DIPEA $(76 \mu \mathrm{L}, 0.43 \mathrm{mmol})$ and copper(I) iodide ( $9 \mathrm{mg}, 0.043 \mathrm{mmol})$. The resulting solution was stirred under argon overnight at room temperature. After dilution with $\mathrm{CH}_{2} \mathrm{Cl}_{2}(100 \mathrm{~mL})$, washing with $1 \mathrm{~mol} / \mathrm{L} \mathrm{HCl}(15 \mathrm{~mL})$, saturated aqueous $\mathrm{NaHCO}_{3}(30 \mathrm{~mL})$, and brine $(15 \mathrm{~mL})$, the organic phase was dried over $\mathrm{Na}_{2} \mathrm{SO}_{4}$ and evaporated under reduced pressure. The crude product was purified by silica gel chromatography eluting (with ethyl acetate/ether (9:1) to ethyl acetate/isopropanol (9:1)) to give the per-acetylated Tbf-PEG-Man-9 (98 mg, 68\% yield) as a yellowish oil: $R_{\mathrm{f}}=0.33\left(\mathrm{CH}_{2} \mathrm{Cl}_{2} / \mathrm{MeOH} 20: 1\right) \cdot[\alpha]_{\mathrm{D}}=$ +36.8 (c 1.0, $\mathrm{CHCl}_{3}$ ). ${ }^{1} \mathrm{H} \mathrm{NMR}\left(500 \mathrm{MHz}, \mathrm{CDCl}_{3}\right) \delta: 8.76$ 
$(\mathrm{t}, J=7.9,4 \mathrm{H}), 8.52(\mathrm{~d}, J=8.4,2 \mathrm{H}), 8.18(\mathrm{~d}, J=7.4,2 \mathrm{H})$, $7.69-7.63(\mathrm{~m}, 6 \mathrm{H}), 7.56(\mathrm{t}, J=7.4,2 \mathrm{H}), 7.08(\mathrm{t}, J=5.7$, $1 \mathrm{H}), 5.92(\mathrm{~s}, 1 \mathrm{H}), 5.30-5.22(\mathrm{~m}, 4 \mathrm{H}), 5.18(\mathrm{dd}, J=9.94, J$ $=3.2,1 \mathrm{H}), 4.32-4.25(\mathrm{~m}, 2 \mathrm{H}), 4.06(\mathrm{dd}, J=10.2, J=1.8$, 1H), $3.89(\mathrm{t}, J=5.32,2 \mathrm{H}), 3.83-3.81(\mathrm{~m}, 4 \mathrm{H}), 3.42-3.35$ $(\mathrm{m}, 4 \mathrm{H}), 3.25(\mathrm{t}, J=5.1,2 \mathrm{H}), 3.21-3.19(\mathrm{~m}, 2 \mathrm{H}), 3.13$ $3.09(\mathrm{~m}, 4 \mathrm{H}), 2.73-2.62(\mathrm{~m}, 2 \mathrm{H}), 2.10(\mathrm{~s}, 3 \mathrm{H}), 2.03(\mathrm{~s}$, $3 \mathrm{H}), 2.00(\mathrm{~s}, 3 \mathrm{H}), 1.94(\mathrm{~s}, 3 \mathrm{H}) .{ }^{13} \mathrm{C} \mathrm{NMR}(125.7 \mathrm{MHz}$, $\left.\mathrm{CDCl}_{3}\right) \delta: 170.6,170.0,169.9,169.8,169.7,143.9,137.0$, $131.4,130.4,128.6,127.9,127.3,127.1,126.2,125.9$, 125.1, 124.9, 123.7, 123.5, 122.0, 82.4, 70.9, 70.7, 70.3, 70.1, 69.9, 69.4, 69.2, 69.0, 66.2, 62.4, 49.7, 46.9, 38.0, 31.3, 31.1, 20.9, 20.7, 20.6. HRMS calcd. for $\mathrm{C}_{56} \mathrm{H}_{59} \mathrm{~N}_{4} \mathrm{O}_{13} \mathrm{~S}$ $[\mathrm{M}]^{+}: \mathrm{m} / z$ 1027.3799, found: 1027.3820.

To a solution of per-acetylated Tbf-PEG-Man-9 (50 mg, $0.048 \mathrm{mmol})$ in dry $\mathrm{MeOH}(3 \mathrm{~mL})$ was added $\mathrm{NaOMe}(1.1 \mathrm{mg}, 0.02 \mathrm{mmol})$. The reaction was allowed to proceed at room temperature for $1 \mathrm{~h}$ at which time the reaction was judged complete by TLC analysis. A sufficient quantity of Amberlyst Ir-120 (plus) $\left(\mathrm{H}^{+}\right.$ form) resin was added to the mixture to render the $\mathrm{pH}$ of the solution neutral. The resin was removed by filtration and the solvent removed under vacuum. The crude product was purified by size-exclusion chromatography (Sephadex ${ }^{\circledR}$ G20), eluting with $\mathrm{CH}_{2} \mathrm{Cl}_{2} / \mathrm{MeOH}$ 9:1. Lyophylization of the solvent gave Tbf-PEG-Man-9 (38 mg, 90\%) as a yellow solid: $R_{\mathrm{f}}=0.33\left(\mathrm{CH}_{2} \mathrm{Cl}_{2} / \mathrm{MeOH} 9: 1\right) ;[\alpha]_{\mathrm{D}}=+29.5$ (c 1.0, $\left.\mathrm{MeOH}\right)$.

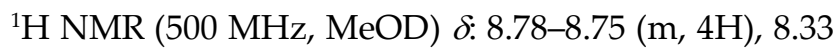
$(\mathrm{d}, J=8.1,2 \mathrm{H}), 8.20(\mathrm{~d}, J=7.8,2 \mathrm{H}), 7.70-7.61(\mathrm{~m}, 6 \mathrm{H})$, $7.49(\mathrm{t}, J=7.3,2 \mathrm{H}), 5.79(\mathrm{~s}, 1 \mathrm{H}), 5.24(\mathrm{~s}, 1 \mathrm{H}), 5.00(\mathrm{t}, J=$ $4.5,1 \mathrm{H}), 3.89-3.84(\mathrm{~m}, 3 \mathrm{H}), 3.83(\mathrm{~s}, 2 \mathrm{H}), 3.78(\mathrm{~d}, J=4.7$, $2 \mathrm{H}), 3.75-3.69(\mathrm{~m}, 3 \mathrm{H}), 3.66-3.60(\mathrm{~m}, 2 \mathrm{H}), 3.43-3.36$ $(\mathrm{m}, 4 \mathrm{H}), 3.23-3.21(\mathrm{~m}, 2 \mathrm{H}), 3.06-3.03(\mathrm{~m}, 4 \mathrm{H}), 2.96-$ $2.94(\mathrm{~m}, 2 \mathrm{H}), 2.77-2.57(\mathrm{~m}, 2 \mathrm{H}) .{ }^{13} \mathrm{C}$ NMR $(125.7 \mathrm{MHz}$, MeOD) $\delta$ : 173.6, 145.6, 138.7, 133.6, 132.6, 130.6, 129.8, 129.6, 129.1, 128.5, 128.3, 128.0, 126.9, 126.7, 125.7, 125.6, 124.2, 87.4, 76.1, 74.5, 74.0, 72.6, 72.0, 71.9, 71.8, 70.7, 69.8, 63.7, 51.4, 50.4, 49.4, 48.5, 40.5, 32.4, 32.2. HRMS calcd. for $\mathrm{C}_{48} \mathrm{H}_{50} \mathrm{~N}_{4} \mathrm{O}_{9} \mathrm{SNa}[\mathrm{M}+\mathrm{Na}]^{+}: \mathrm{m} / \mathrm{z}$ 881.3196, found: 881.3250 .

\subsection{Functionalization of MWCNTs with the neoglycolipids}

In a typical preparation, $4 \mathrm{mg}$ of MWCNTs were suspended in $5 \mathrm{~mL}$ of aqueous solution containing $4 \mathrm{mg}$ of the neoglycolipid. The mixture was sonicated using a water-bath sonicator for $1 \mathrm{~h}$, incubated overnight, and then sonicated for another $30 \mathrm{~min}$. Insoluble materials and impurities (amorphous carbon and catalyst) were then removed by low-speed centrifugation at $3000 \mathrm{r} / \mathrm{min}$ for $5 \mathrm{~min}$. A second high-speed centrifugation at $14,000 \mathrm{r} / \mathrm{min}$ for $12 \mathrm{~min}$ was then performed to sediment the stable aggregates, and eliminate the excess neoglycolipids that remained in the supernatant solution. After lyophilization, stable black solutions free of any visible particulates were obtained, indicating the absence of large bundles, with solubility values of $3.4 \mathrm{mg} / \mathrm{mL}$ in the case of MWCNTTbf-PEG-Lac-8, and $1.4 \mathrm{mg} / \mathrm{mL}$ in the case of MWCNTPy-PEG-Lac-10. The absence of aggregation is also supported by TEM images, which typically show mainly individual nanotubes (see Fig. S-1 in the Electronic Supplementary Material (ESM)).

\subsection{Lectin binding assay}

A $1 \mathrm{~mL}$ solution of peanut agglutin labeled with fluorescein isothiocyanate (PNA-FITC) $(100 \mu \mathrm{g} / \mathrm{mL})$ in buffer $(0.10 \mathrm{~mol} / \mathrm{L}$ Tris, and $0.15 \mathrm{~mol} / \mathrm{L} \mathrm{NaCl}, \mathrm{pH} 8.0)$ was added to a suspension of amphiphile-coated nanotubes in water $(0.3 \mathrm{mg} / \mathrm{mL})$. An additional $0.5 \mathrm{~mL}$ of buffer solution was added and the reaction was incubated overnight at room temperature in the dark. Lactose inhibition of PNA binding to the MWCNT aggregates was tested by preincubating $1 \mathrm{~mL}$ of PNAFITC solution in buffer $(100 \mu \mathrm{g} / \mathrm{mL})$ with $0.5 \mathrm{~mL}$ of lactose in buffer $(500 \mathrm{mg} / \mathrm{mL})$ for $1 \mathrm{~h}$ at room temperature in the dark. This preincubated solution was added to the suspension of MWCNT aggregates in water $(1 \mathrm{~mL})$, and the resulting solution was incubated overnight at room temperature in the dark, as described above. After incubation, the solutions were centrifuged three times at $14,000 \mathrm{r} / \mathrm{min}$ for $10 \mathrm{~min}$ to remove the unreacted lectins. The centrifuged solutions were dissolved in $100 \mu \mathrm{L}$ of buffer and their fluorescence intensities at 510-550 nm were determined using a fluorescence microplate reader (excitation wavelength $492 \mathrm{~nm})$. 


\section{Results and discussion}

\subsection{Chemistry}

Experimental [26, 46, 47], and theoretical studies [48] have shown that the strength of the $\pi-\pi$ interactions between aromatic molecules and surface of carbon nanotubes increases with the size of the aromatic species and depends on the substituents in the aromatic ring. Additionally, based on work with the planar sheets of graphene, the physiosorption of aromatics onto the nanotube sidewalls through $\pi-\pi$ stacking is assumed to take place in a coplanar geometry [49]. Nevertheless, due to the intrinsic curvature of the rolled nanotube surface, the shape of the aromatic moiety can also influence the affinity $[46,50]$. Hence, sugars functionalized with Tbf, a polyaromatic compound that exhibits a high affinity for porous graphitized carbon [51-53], and possesses a topology that resembles a butterfly with open wings (Scheme 1) are expected to solvate MWCNTs through $\pi-\pi$ interactions better than those functionalized with the widely used pyrene tail (Scheme 1) [31, 44, 45]. This hypothesis is shown in Scheme 1, where the sugarbased Tbf amphiphilic compound I that contains a hydrophilic spacer interacts with the CNT surface leading to robust nanoglycoarrays with a multivalent presentation of sugar epitopes.

In order to develop a general and efficient bioconjugation of the Tbf polyaromatic tail to a given biomolecule in general and to glycoligands in particular, we made use of the unsurpassed copper-catalyzed azide-alkyne cycloaddition (CuAAC), the paradigmatic example of "click chemistry", which offers the advantages of good yield, mild reaction conditions and broad tolerance towards functional groups $[54,55]$. To achieve this goal, we installed the azido function on the sugar part of the amphiphile, and developed a three-step synthesis of a novel alkyne-functionalized Tbf (5). The $8 b H$-tetrabenzo[ $a, c, g, i]$ fluorene (Tbf-H) (3) is easily synthesized on a multigram scale starting from commercially available 9-bromophenanthrene (1) using a reported procedure, via the symmetrical alcohol (2) [56]. Then the formation of the tetrabutylammonium salt of Tbf (4), by treatment of (3) with $\mathrm{NBu}_{4} \mathrm{OH}$, followed by immediate reaction with propargyl bromide at room temperature provided the desired Tbf alkyne (5) in excellent isolated yield (Scheme 2).

The targeted Tbf-linked carbohydrate compounds Tbf-PEG-Lac-8 and Tbf-PEG-Man-9, were then obtained in a straightforward manner by copper(I)catalyzed azide-alkyne cycloaddition reactions of our recently reported azido sugars (6) and (7), with the alkyne-derivatized fluorene (5). Finally, Zemplen deacetylation, followed by purification of the free sugars on Sephadex G-20 yielded the water-soluble neoglycoconjugates shown in Scheme 3.

\subsection{Functionalization of MWCNTs}

We next studied the ability of these Tbf-tethered sugar molecules to exfoliate MWCNTs and to form robust water soluble bioactive nanoglycoarrays. By merely mixing either Tbf-PEG-Lac-8 or Tbf-PEG-Man-9 with MWCNTs in pure water without any additive, followed by sonication for $1 \mathrm{~h}$, a characteristic black stable suspension was obtained, indicating the formation of stable MWCNT-Tbf-PEG-Lac-8 and MWCNT-TbfPEG-Man-9 soluble aggregates, respectively (Fig. 1, vials (b) and (c)).

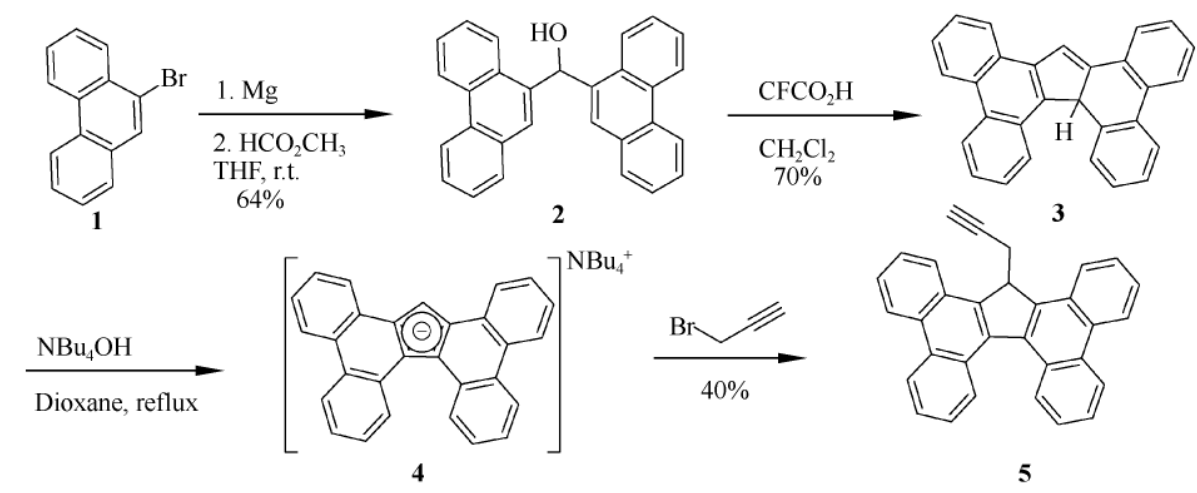

Scheme 2 Synthesis of the Tbf-tethered alkyne (5) 


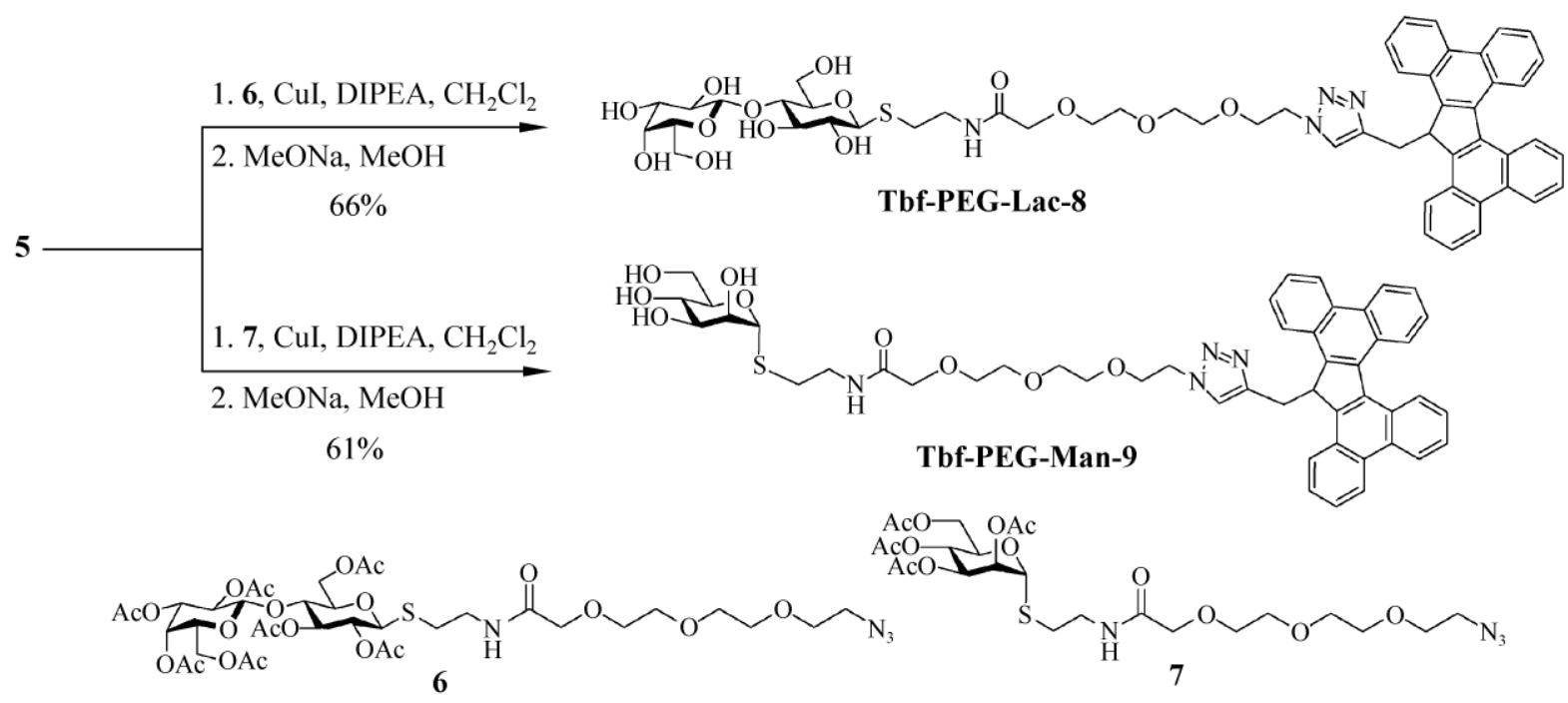

Scheme 3 Synthesis of the fluorene-functionalized neoglycolipid derivatives

The resulting suspension remained stable for several months whereas, in contrast, the sonication of MWCNTs in water without the sugar amphiphiles, led to unstable suspensions resulting in the rapid precipitation of the black CNTs after a few minutes (Fig. 1, vial (a)). The observation of a stable black suspension when Tbf-PEG-Lac-8 or Tbf-PEG-Man-9 are used, shows the change in the native hydrophobic characteristics of the nanotube side wall, which can become more hydrophilic after functionalization of the MWCNTs surface with glycolipids and the exposition of the sugar epitopes towards the polar water phase.

The MWCNT-nanoglycoarrays were characterized by TEM, SEM, and UV-vis, IR, fluorescence, and Raman spectroscopies. Furthermore, in order to determine the nature of the supramolecular interaction

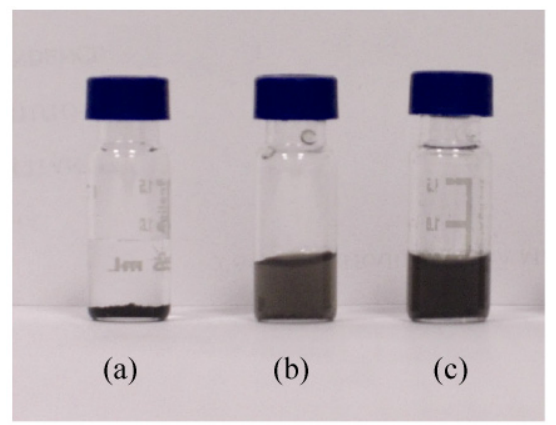

Figure 1 Photographs of vials with aqueous solutions of: (a) as produced MWCNTs, (b) MWCNT-Tbf-PEG-Lac-8, (c) MWCNTTbf-PEG-Man-9 between the Tbf-functionalized amphiphiles and the surface of the CNTs, and to establish the strength and efficiency of these interactions-which are responsible for the solubilisation of MWCNTs - the results were compared with those obtained for related compounds functionalized with a pyrene tail. Therefore, amphiphiles Py-PEG-Lac-10 and Py-PEG-Man-11, with the same sugar epitopes as molecules (8) and (9) (lactose and mannose respectively) were synthesized following a similar approach to that described earlier, in which the key step is the [2+3] Huisgen cycloaddition using as alkyne the pyrene-derived alkyne 12 (Fig. 2). Details are given in the ESM.

\subsection{Characterization of the aggregates}

Initial evidence for the formation of stable exfoliated MWCNT-Tbf-PEG-sugar aggregates came from TEM and SEM analysis, obtained by analyzing $15 \mu \mathrm{L}$ of diluted aqueous stable solutions on a copper-coated holey carbon grid. As a consequence of the hydrophobic interactions, van der Waals forces, and $\pi$-stacking of individual nanotubes, as produced CNTs usually exist as dense bundles or ropes that are deeply interconnected as shown in Figs. 3(a) and 3(c).

Quite remarkably, functionalization with the neoglycolipids Tbf-PEG-Lac-8 and Tbf-PEG-Man-9 in pure water under strictly neutral conditions, allowed the CNT bundles to exfoliate producing small, mainly 


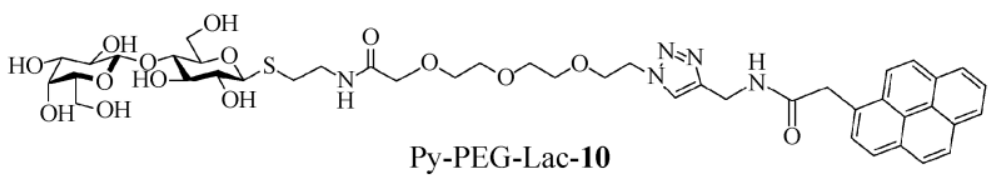<smiles></smiles>

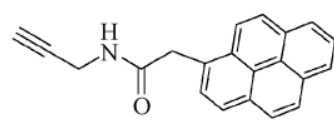

12

Figure 2 Structure of pyrene-based neoglycolipids derivatives used in this study

individual, sugar coated nanotubes, as evidenced by TEM and SEM analysis (Figs. 3(b) and 3(d); see Fig. S-2 in the ESM for TEM and SEM images of MWCNT-Tbf-PEG-Man-9, MWCNT-Py-PEG-Lac-10, and MWCNT-Py-PEG-Man-11). The UV-vis spectra of MWCNT-Tbf-PEG-Lac-8 aggregates (Fig. 4(a), red curve) differ significantly from the free amphiphile Tbf-PEG-Lac-8. Indeed, due probably to the strong interaction of the polyaromatic Tbf group with MWCNTs, the intensity of the absorbance of the aggregates was drastically decreased compared to that observed for the free amphiphile in solution (Fig. 4(a) black curve, see Fig. S-3 in the ESM for further spectra). In contrast, apart from a slight decrease in intensity, the UV-vis spectra for the MWCNT-Py-PEG-Lac-10 aggregates (Fig. 4(b), red curve) were almost identical

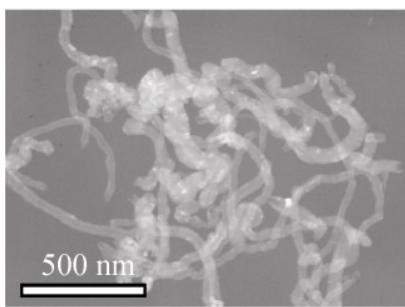

(a)

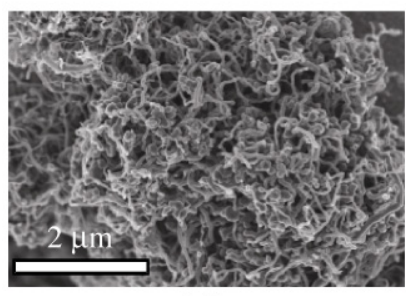

(c)

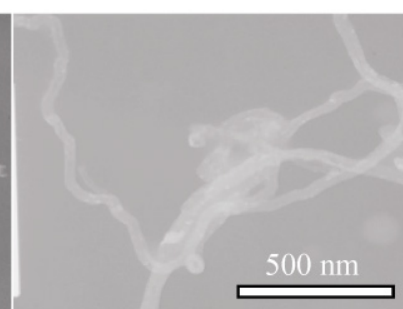

(b)

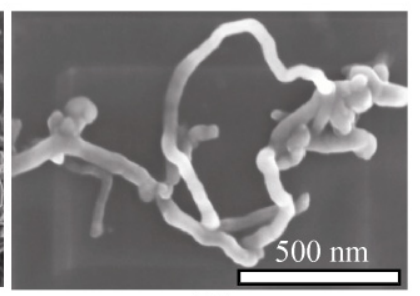

(d)
Figure 3 (a) TEM image of MWCNTs. (b) TEM image of MWCNT-Tbf-PEG-Lac-8. (c) SEM image of MWCNTs. (d) SEM image of MWCNT-Tbf-PEG-Lac-8 to the neoglycolipid Py-PEG-Lac-10 alone (Fig. 4(b), black curve), indicative of the weak interaction of the pyrene moiety with the sidewall of MWCNTs.

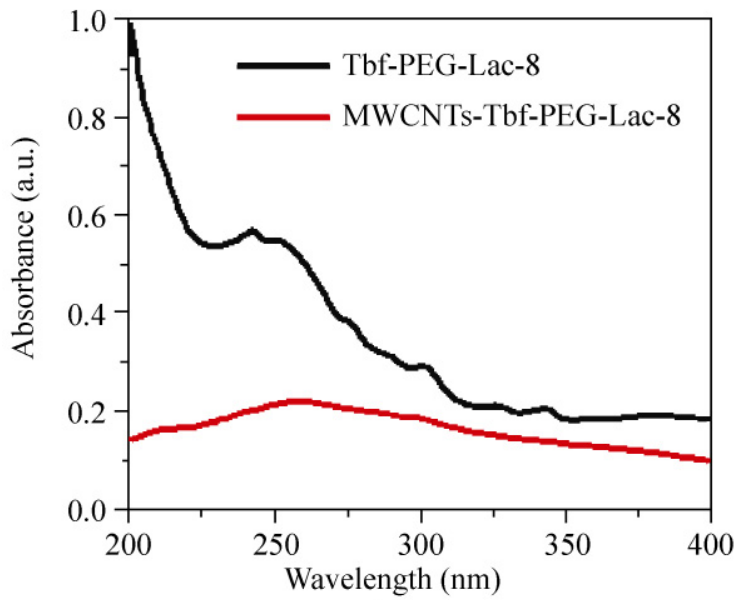

(a)

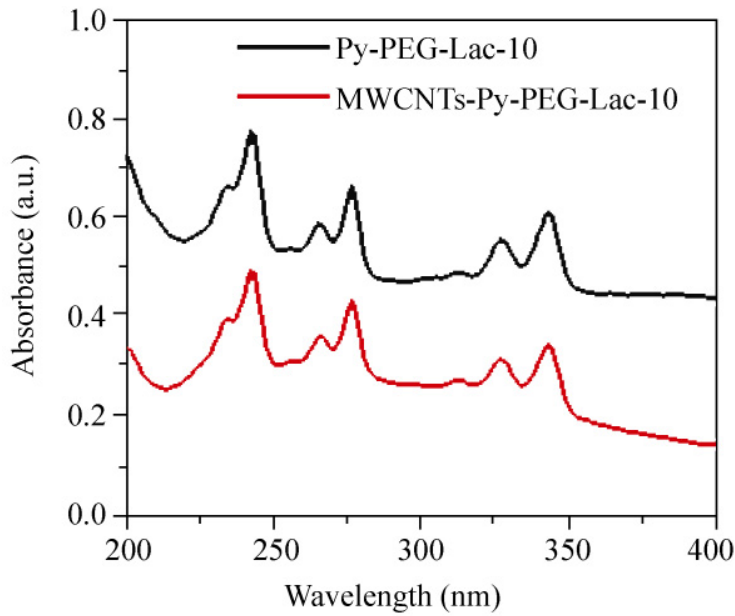

(b)

Figure 4 (a) UV-vis spectra of Tbf-PEG-Lac-8 (black line), and aggregate MWCNT-Tbf-PEG-Lac-8 (red line). (b) UV-vis spectra of Py-PEG-Lac-10 (black line), and aggregate MWCNTPy-PEG-Lac-10 (red line) 
The analysis of the IR spectra of the MWCNTs functionalized with the disaccharide amphiphiles Tbf-PEG-Lac-8 and Py-PEG-Lac-10 afforded more evidence in favour of the $\pi-\pi$ stacking interaction of the Tbf and Py tails with the nanotube sidewalls.

The intensity of the band at $2923 \mathrm{~cm}^{-1}\left(v \mathrm{C}_{\mathrm{sp2}}-\mathrm{H}\right.$ stretching) was lower in the IR spectra of both aggregates, MWCNT-Tbf-PEG-Lac-8 (Fig. 5(a), red spectrum), and MWCNT-Py-PEG-Lac-10 (Fig. 5(b), red spectrum) compared to the spectra of the free sugar based molecules. The intensity of this band is drastically decreased in the case of the aggregate MWCNT-Tbf-PEG-Lac-8 compared to the free glycolipid Tbf-PEG-Lac-8, due to the strong interaction between the aromatic rings of the fluorene and the MWCNT sidewalls (Fig. 5(a), see also Fig. S-4 in the ESM for further spectra) [57].

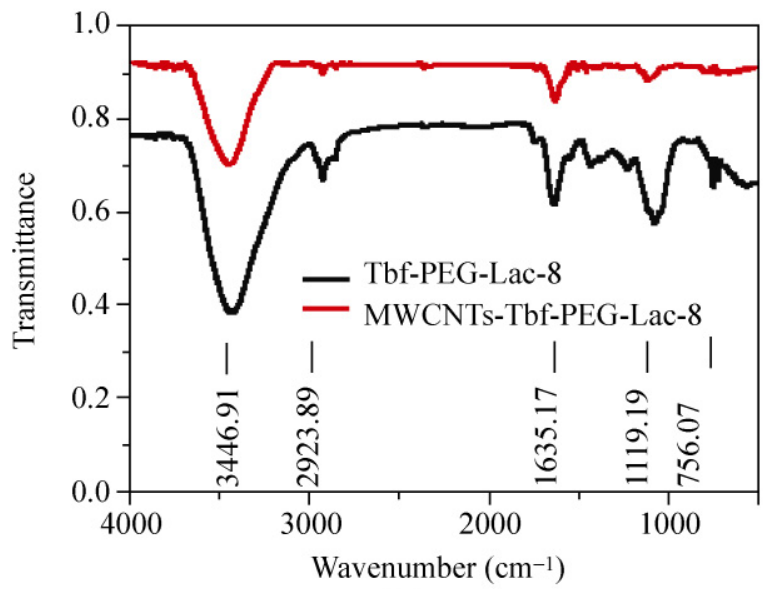

(a)

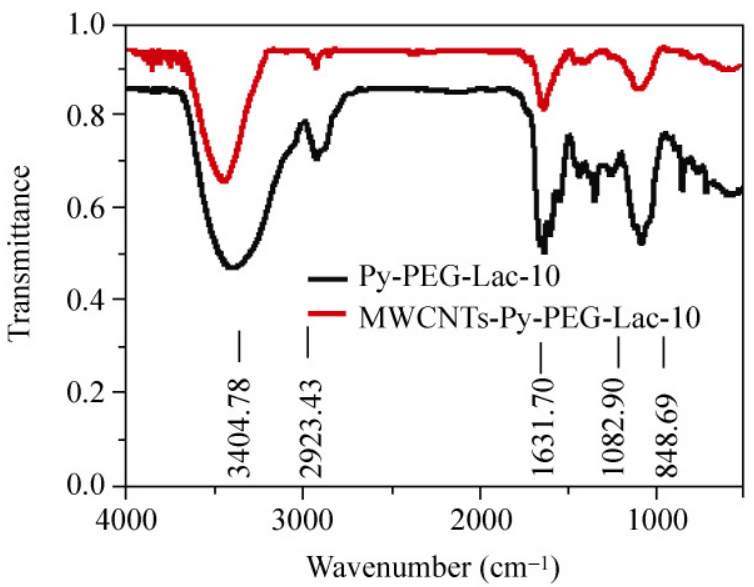

(b)

Figure 5 (a) IR spectra of Tbf-PEG-Lac-8 (black line), and aggregate MWCNT-Tbf-PEG-Lac-8 (red line). (b) IR spectra of Py-PEG-Lac-10 (black line), and aggregate MWCNT-Py-PEGLac-10 (red line)
The aggregates were further characterized by Raman spectroscopy (Fig. 6). Resonance Raman spectroscopy has been extensively used to study CNTs [58]. Important information regarding the degree of defects, the nanotube chirality, and the electronic type can be obtained. Table 1 shows the intensity ratio between the $\mathrm{G}$ band ( $\mathrm{sp}^{2}$ hybridization, graphene band) and $\mathrm{D}$ band ( $\mathrm{sp}^{3}$ hybridization, disordered band) of MWCNTs, and the aggregates of the MWCNTs with the neoglycolipids Tbf-PEG-Lac-8, Tbf-PEG-Man-9, Py-PEG-Lac-10, and Py-PEG-Man-11. Interestingly, as shown in Table 1 , the intensity ratio $\left(I_{G} / I_{D}\right)$ for the aggregates MWCNT-Tbf-PEG-Lac-8 and MWCNTTbf-PEG-Man-9 is significantly increased, when compared with the value for the unmodified MWCNTs, while this ratio remains almost unchanged for

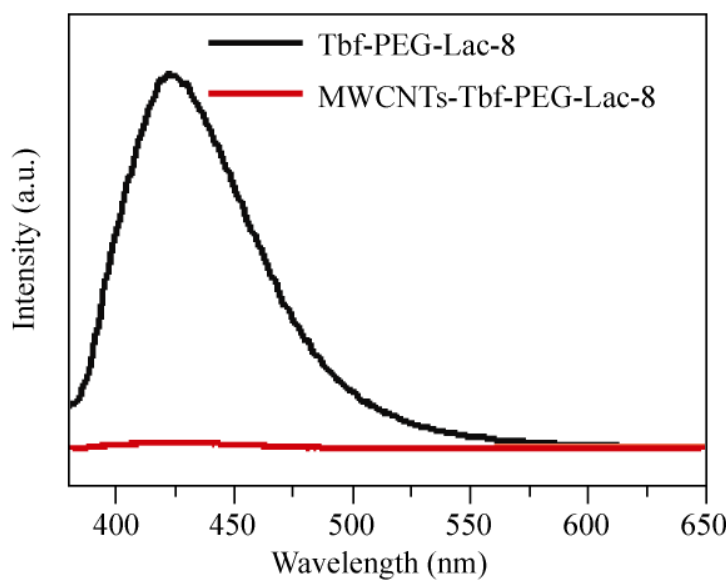

(a)

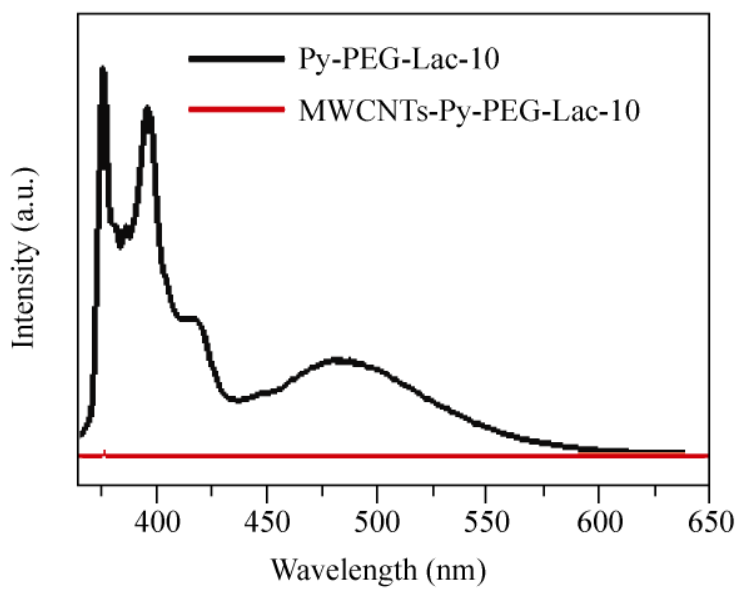

(b)

Figure 6 (a) Fluorescence spectra of Tbf-PEG-Lac-8 (black line), and aggregate MWCNT-Tbf-PEG-Lac-8 (red line). (b) Fluorescence spectra of Py-PEG-Lac-10 (black line), and aggregate MWCNTPy-PEG-Lac-10 (red line) 
Table 1 Raman data for the functionalized MWCNTs and the starting nanotubes excited at $532.14 \mathrm{~nm}$

\begin{tabular}{lccc}
\hline \multicolumn{1}{c}{ Sample } & G band & D band & Ratio G/D \\
\hline MWCNTs & 1.74 & 2.00 & 0.87 \\
MWCNT-Py-PEG-Man-11 & 1.50 & 1.70 & 0.88 \\
MWCNT-Py-PEG-Lac-10 & 1.63 & 1.81 & 0.90 \\
MWCNT-Tbf-PEG-Man-9 & 2.16 & 2.17 & 1.00 \\
MWCNT-Tbf-PEG-Lac-8 & 1.33 & 1.20 & 1.11 \\
\hline
\end{tabular}

MWCNT-Py-PEG-Lac-10 and MWCNT-Py-PEG-

Man-11. This might be indicative of the possible selective functionalization of MWCNTs with a low level of sidewall defects by amphiphiles with the butterflylike aromatic tail of Tbf, leaving the other CNTs with a high level of defects level unfunctionalized.

Taken together, these results also confirm the nondestructive nature of the functionalization strategy developed and, more importantly, the sorting effect of the CNTs, thus, validating the non-covalent interaction of the functional sugar based Tbf molecules with the surface of the CNTs.

Fluorescence spectra provide direct evidence for the interaction between the Tbf-PEG-sugars (8 and 10) and the MWCNTs. As shown in Fig. 6, the excimer emission from the Tbf moiety in the aggregate solution was considerably quenched compared to that of the original solution containing the amphiphile alone. This quenching effect can be explained by invoking an energy transfer from the polyaromatic tail group Tbf to the $\pi$-extended system of the nanotube surface. The same behaviour has already been observed in the case of CNTs tethered with pyrene, as well as in the case of CNTs tethered with porphyrins [59, 60].

The amount of CNT-immobilized Tbf-PEG-Lac-8 was estimated by TGA. For the MWCNT-Tbf-PEGLac-8 the mass loss was approximately $60 \%$ at $600{ }^{\circ} \mathrm{C}$, (Fig. 7(a)). At the same temperature, Tbf-PEG-Lac-8 showed a mass loss of $70 \%$. Using these data, we estimate that the complete destruction of Tbf-PEGLac- 8 in the aggregate would cause a mass loss of about $85 \%$, which indicates that most of the CNT sidewalls are covered with the glycolipid.

For the purposes of comparison, we performed the same study with the aggregate MWCNT-Py-PEGLac-10 formed between CNT and the pyrene-tethered glycolipid. In this case, the mass loss at $600{ }^{\circ} \mathrm{C}$ was
$26 \%$ (Fig. 7(b)), which confirms the stronger interaction of the fluorene derivatives with the MWCNTs relative to the pyrene group (other TGA traces are given in Fig. S-6 in the ESM).

\subsection{Specific interaction with Arachis hypogea (peanut) lectin}

A key issue in the present research is the selectivity acquired by the CNT-carbohydrate aggregates toward specific receptors as a consequence of the multivalent display of sugar epitopes. In order to study this specific binding feature, important for future biological applications of the prepared bionanomaterials, we make use of the known lactose-Arachis hypogea peanut agglutinin (lactose-PNA) specificity [61]. Based on the

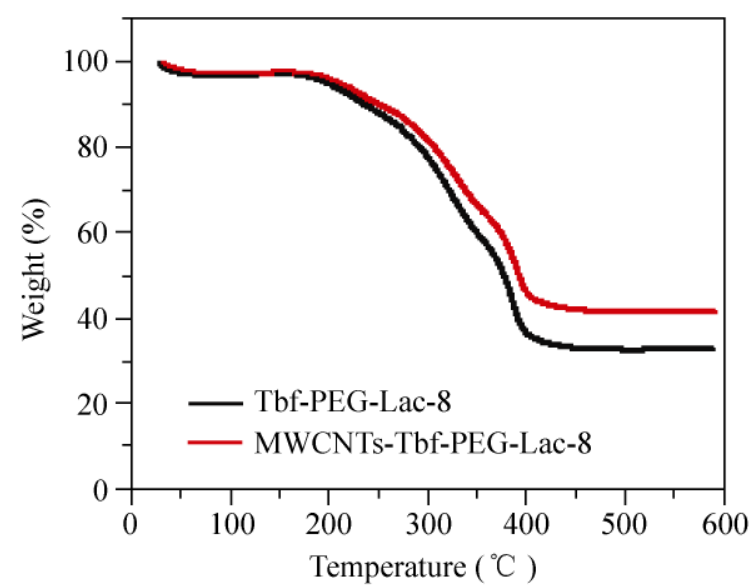

(a)

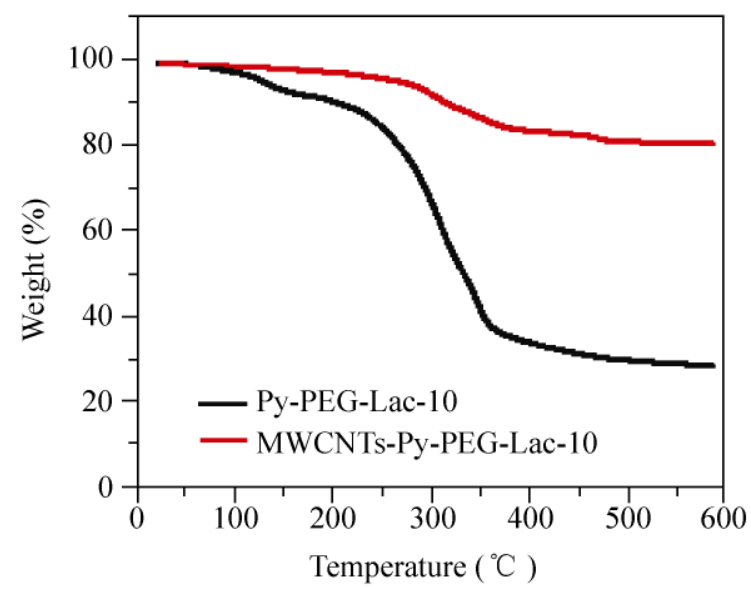

(b)

Figure 7 (a) Thermogravimetric analysis of Tbf-PEG-Lac-8 (black line), and aggregate MWCNT-Tbf-PEG-Lac-8 (red line). (b) Thermogravimetric analysis of Py-PEG-Lac-10 (black line), and aggregate MWCNT-Py-PEG-Lac-10 (red line) 
TGA results, which showed that MWCNT-Tbf-PEGLac-8 aggregates exhibit a large number of lactose residues onto the nanotube surface, we anticipated that these aggregates could be recognized by a specific lectin in a better way than MWCNT-Py-PEG-Lac-10 aggregates with the pyrene counterparts (Fig. 8(a)).
To test this hypothesis, freshly prepared MWCNTTbf-PEG-Lac-8 and MWCNT-Py-PEG-Lac-10 aggregates were incubated with fluorescein isothiocyanate conjugated lectin PNA-FITC in Tris buffer at $\mathrm{pH} 8$. The excess fluorescent lectin was then removed by series of centrifugations at 14,000 r/min followed by

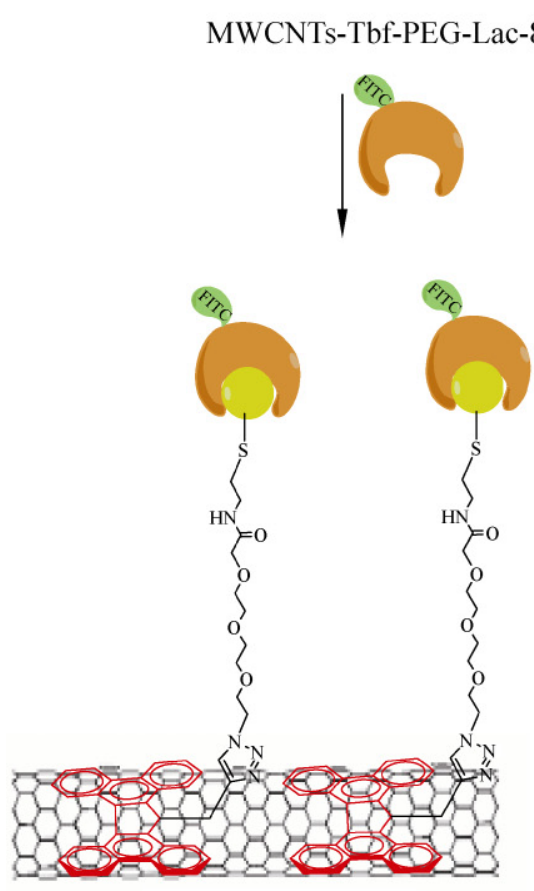

Specific binding

( I )

PNA
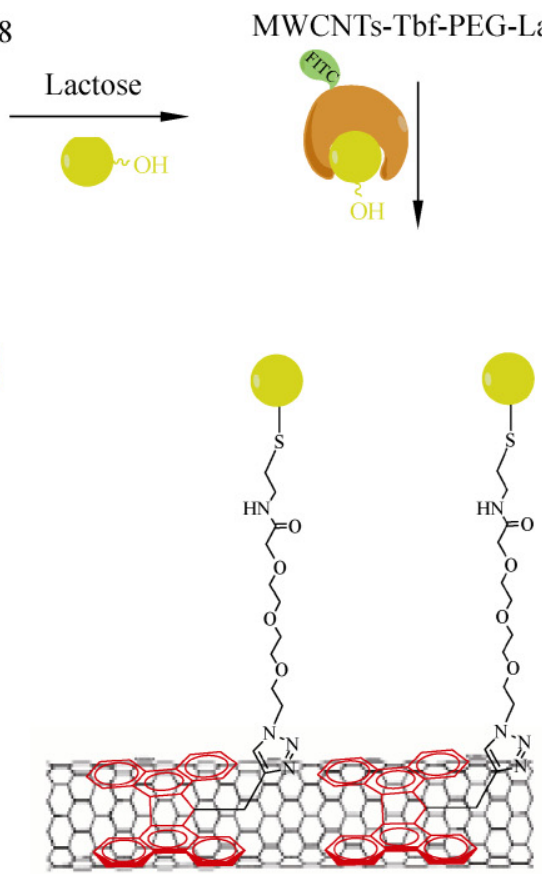

No binding

(II)

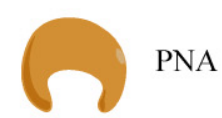

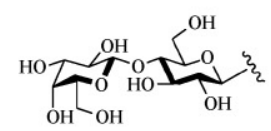

(a)

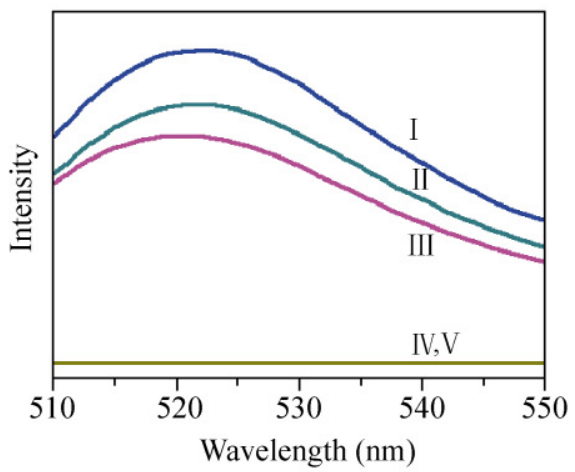

(b)
MWCNTs-Tbf-PEG-Man-9

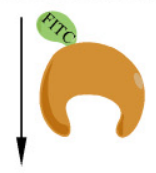

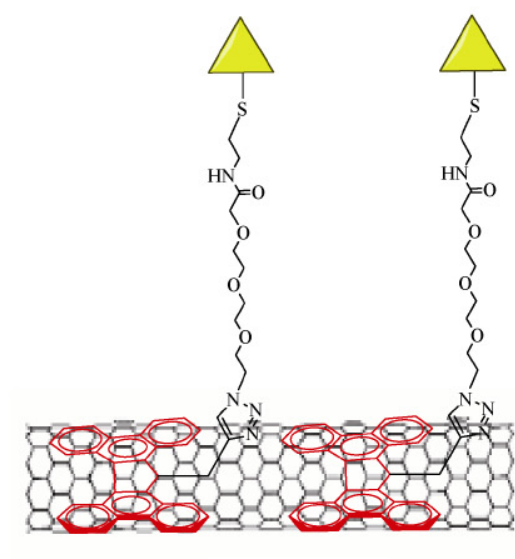

No binding

(III)

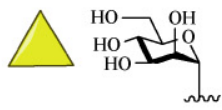

Figure 8 (a) Schematic representation of ( I ) specific binding of PNA to the MWCNT-Tbf-PEG-Lac-8 surface, (II) inhibition of the specific binding by soluble lactose, (III) absence of binding of PNA to mannose coated nanoglycoarrays MWCNT-Tbf-PEG-Man-9. (b) Fluorescence spectra of ( I ) PNA-FITC, ( II ) PNA-FITC with MWCNT-Tbf-PEG-Lac-8, (III) PNA-FITC with MWCNT-Py-PEGLac-10, (IV) PNA-FITC, previously incubated with lactose, with MWCNT-Tbf-PEG-Lac-8, (V) PNA-FITC with MWCNT-TbfPEG-Man-9 
elimination of the supernatant, and resuspension of the pellet in the same buffer. Subsequently, the formation of the CNT-Tbf-PEG-Lac-8-PNA-FITC multicomposite was determined by fluorescence spectroscopy, (Fig. 8(b)). While both MWCNT-TbfPEG-Lac-8 and MWCNT-Py-PEG-Lac-10 samples exhibited positive responses (Figs. 8(b)-(II) and 8(b)-(III)), significant fluorescence was only observed with the former system (Fig. 8(b)-( II )), attributed to a high level of bound fluorescent lectin, indicative of a high lactose epitope concentration on the surface of the CNTs. To show that the observed fluorescence is a consequence of the specific binding of the glycoligand to its specific receptor, and not to the well documented non-specific interaction of the nanotubes with proteins [62], two negative control experiments were carried out. The initial one involved the preincubation of PNA lectin with free lactose prior to the incubation with the aggregate, (Fig. 8(a)-( II )). In this case the formation of the PNA-FITC-MWCNTTbf-PEG-Lac-8 multicomposite was drastically inhibited (Fig. 8(b)-(IV)), showing unambiguously that the fluorescence tagging was driven by the specific PNA-lactose interaction. In the second control, we performed the same experiment with the aggregate MWCNT-Tbf-PEG-Man-9, displaying an $\alpha$-mannose epitope on its outer surface, which should not be recognized by PNA lectin, (Fig. 8(a)-(III)). This was indeed the case, as no fluorescence tagging (Fig. 8(b)(V)) was detected, indicating that the biological receptor does not interact with the aggregates bearing unspecific sugar epitopes. Taken all together, these results indicate that once the CNTs are functionalized with Tbf-PEG-glycoligand they acquire biological specificity toward the protein receptors of the glycoligands exposed on their surface.

\section{Conclusions}

We have developed new Tbf-tethered amphiphilic carbohydrates, which interact strongly with MWCNTs via $\pi-\pi$ stacking. These novel functional molecules have been synthesized in a straightforward manner using click chemistry. By means of TGA, UV, IR, and fluorescence spectroscopies, the interaction between
MWCNTs and the Tbf group was shown to be stronger than the one involving pyrene-based amphiphilic carbohydrates. This enhanced interaction can be most likely ascribed to the ability of the butterfly-like polyaromatic structure of Tbf to fit more effectively on the surface of the carbon nanotubes. Resonance Raman spectroscopy analysis suggested that the functionalization process with Tbf amphiphiles might involve mainly MWCNTs with the lowest level of sidewall defects; further calculations and theoretical investigations are underway in order to confirm this hypothesis. The resulting bionanomaterials are of great significance, as carbohydrates are involved in biologically relevant events including cell-cell communication, cell adhesion, inflammation, tumor cell metastasis, and pathogen infections. We have also demonstrated that these novel nanoglycoarrays display selective binding with appropriate biological receptors.

\section{Acknowledgements}

This work was supported by the Ministerio de Ciencia e Innovación (grant No. CTQ2010-21755-CO2-00), the Junta de Andalucía (grant Nos. P06-FQM-01852 and P07-FQM-2774), the Centre National de la Recherche Scientifique (France) and the Consejo Superior de Investigaciones Científicas (Egide Picasso 09543XA and Projets Internationaux de Cooperation Scientifiques Program 2008-2010).

Electronic Supplementary Material: Supplementary material (experimental details for the synthesis of alkyne (12), Py-PEG-Lac-10, Py-PEG-Man-11, and further details of TEM imaging, SEM imaging, UV-vis spectroscopy, IR spectroscopy as well as TGA measurements) is available in the online version of this article at http://dx.doi.org/10.1007/s12274-0100044-2 and is accessible free of charge.

Open Access: This article is distributed under the terms of the Creative Commons Attribution Noncommercial License which permits any noncommercial use, distribution, and reproduction in any medium, provided the original author(s) and source are credited. 


\section{References}

[1] Ijima, S. Helical microtubules of graphitic carbon. Nature 1991, 354, 56-58.

[2] Tanaka, K.; Yamabe, T.; Fukui, K. The Science and Technology of Carbon Nanotubes; Elsevier: Oxford U.K., 1999.

[3] Dresselhaus, M. S.; Dresselhaus, G.; Avouris, P. Carbon Nanotubes: Synthesis, Structure, Properties and Applications; Springer-Verlag: Berlin, 2000.

[4] Lu, F.; Gu, L.; Meziani, M. J.; Wang, X.; Luo, P. G.; Veca, L. M.; Cao, L.; Sun, Y. P. Advances in bioapplications of carbon nanotubes. Adv. Mater. 2009, 21, 139-152.

[5] Liu, Z.; Tabakman, S.; Welsher, K.; Dai, H. Carbon nanotubes in biology and medicine: In vitro and in vivo detection, imaging and drug delivery. Nano Res. 2009, 2, 85-120.

[6] Byon, H. R.; Choi, H. C. Network single-walled carbon nanotube-field effect transistors (SWNT-FETs) with increased schottky contact area for highly sensitive biosensor applications. J. Am. Chem. Soc. 2006, 128, 2188-2189.

[7] Cherukuri, P.; Bachilo, S. M.; Litovsky. S. H.; Weisman, R. B. Near-infrared fluorescence microscopy of single-walled carbon nanotubes in phagocytic cells. J. Am. Chem. Soc. 2004, 126, 15638-15639.

[8] Porter, A. E.; Gass, M.; Muller, K.; Skepper, J. N.; Midgley, P. A.; Welland, M. Direct imaging of single-walled carbon nanotubes in cells. Nat. Nanotechnol. 2007, 2, 713-717.

[9] Welsher, K.; Liu, Z.; Daranciang, D.; Dai, H. Selective probing and imaging of cells with single walled carbon nanotubes as near-infrared fluorescent molecules. Nano Lett. 2008, 8, 586-590.

[10] Bianco, A.; Kostarelos, K.; Prato, M. Applications of carbon nanotubes in drug delivery. Curr. Opin. Chem. Biol. 2005, 9 , 674-679.

[11] Bhirde, A. A.; Patel, V.; Gavard, J.; Zhang, G.; Sousa, A. A.; Masedunskas, A.; Leapman, R. D.; Weigert, R.; Gutkind, J. S.; Rusling, J. F. Targeted killing of cancer cells in vivo and in vitro with EGF-directed carbon nanotube-based drug delivery. ACS Nano 2009, 3, 307-316.

[12] Kam, N. W. S.; Dai, H. Carbon nanotubes as intracellular protein transporters generality and biological functionality. J. Am. Chem. Soc. 2005, 127, 6021-6026.

[13] Pantarotto, D.; Briand, J. P.; Prato, M.; Bianco, A. Translocation of bioactive peptides across cell membranes by carbon nanotubes. Chem. Commun. 2004, 16-17.

[14] Liu, Y.; Wu, D. C.; Zhang, W. D.; Jiang, X.; He, C. B.; Chung, T. S.; Goh, S. H.; Leong, K. W. Polyethylenimine-grafted multiwalled carbon nanotubes for secure noncovalent immobilization and efficient delivery of DNA. Angew. Chem. Int. Ed. 2005, 44, 4782-4785.
[15] Liu, Z.; Winters, M.; Holodniy, M.; Dai, H. siRNA delivery into human $\mathrm{T}$ cells and primary cells with carbon nanotube transporters. Angew. Chem. Int. Ed. 2007, 46, 2023-2027.

[16] Yang, R.; Yang, X.; Zhang, Z.; Zhang, Y.; Wang, S.; Cai, Z.; Jia, Y.; Ma, Y.; Zheng, C.; Lu, Y.; Roden, R.; Chen, Y. Single walled carbon nanotubes-mediated in vivo and in vitro delivery of siRNA into antigen-presenting cells. Gene Ther. 2006, 13, 1714-1723.

[17] Kam, N. W. S.; O’Connell, M.; Wisdom, J. A.; Dai, H. Carbon nanotubes as multifunctional biological transporters and near-infrared agents for selective cancer cell destruction. Proc. Natl. Acad. Sc. USA. 2005, 102, 11600-11605.

[18] Chakravarty, P.; Marches, R.; Zimmerman, N. S.; Swafford, A. D. E.; Bajaj, P.; Musselman, I. H.; Pantano, P.; Draper, R. K.; Vitetta. E. S. Thermal ablation of tumor cells with antibody-functionalized single-walled carbon nanotubes. Proc. Nat. Acad. Sci. USA 2008, 105, 8697-8702.

[19] Gannon, C. J.; Cherukuri, P.; Yakobson, B. I.; Cognet, L.; Kanzius, J. S.; Kittrell, C.; Weisman, R. B.; Pasquali, M.; Schmidt, H. K.; Smalley, R. E.; Curley, S. A. Carbon nanotube-enhanced thermal destruction of cancer cells in a noninvasive radiofrequency field. Cancer 2007, 110, 26542665.

[20] Singh, R.; Pantarotto, D.; Lacerda, L.; Pastorin, G.; Klumpp, C.; Prato, M.; Bianco, A.; Kostarelos, K. Tissue biodistribution and blood clearance rates of intravenously administered carbon nanotube radiotracers. Proc. Natl. Acad. Sci. USA 2006, 103, 3357-3362.

[21] Liu, Z.; Davis, C.; Cai, W.; He, L.; Chen, X.; Dai, H. Circulation and long-term fate of functionalized, biocompatible single-walled carbon nanotubes in mice probed by Raman spectroscopy. Proc. Natl. Acad. Sci. USA 2008, 105, 14101415.

[22] Schipper, M. L.; Nakayama-Ratchford, N.; Davis, C. R.; Kam, N. W. S.; Chu, P.; Liu, Z.; Sun, X.; Dai, H.; Gambhir, S. S. A pilot toxicology study of single-walled carbon nanotubes in a small sample of mice. Nature Nanotech. 2008, 3, 216-221.

[23] Sudibya, H. G.; Ma, J.; Dong, X.; Ng, S.; Li, L. J.; Liu, X. $\mathrm{W}$; Chen, P. Interfacing glycosylated carbon-nanotubenetwork devices with living cells to detect dynamic secretion of biomolecules. Angew. Chem. Int. Ed. 2009, 48, 2723-2726.

[24] Tasis, D.; Tagmatarchis, N.; Bianco, A.; Prato, M. Chemistry of carbon nanotubes. Chem. Rev. 2006, 106, 1105-1136.

[25] Britz, D. A.; Khlobystov, A. N. Noncovalent interactions of molecules with single walled carbon nanotubes. Chem. Soc. Rev. 2006, 35, 637-659.

[26] Hahn, U.; Engmann, S.; Oelsner, C.; Ehli, C.; Guldi, D. M.; Torres, T. Immobilizing water-soluble dendritic electron 
donors and electron acceptors-phtalocyanines and perylendiimide-onto single Wall carbon nanotubes. J. Am. Chem. Soc. 2010, 132, 6392-6401.

[27] Chen, R. J.; Zhang, Y.; Wang, D.; Dai, H. Noncovalent sidwall functionalization of single-walled carbon nanotubes for protein immobilization. J. Am. Chem. Soc. 2001, 123, 3838-3839.

[28] Nakashima, N.; Tomonari, Y.; Murakami, H. Water-soluble single-walled carbon nanotubes via non-covalent sidewallfunctionalization with a pyrene-carrying ammonium ion. Chem. Lett. 2002, 638-639.

[29] Georgakilas, V.; Tzitzios, V.; Gournis, D.; Petridis, D. Attachement of magnetic nanoparticles on carbon nanotubes and their soluble derivatives. Chem Mater. 2005, 17, 16131617.

[30] Liu, Z.; Sun, X.; Nakayama-Ratchford, N.; Dai, H. Supramolecular chemistry on water-soluble carbon nanotubes for drug loading and delivery. ACS Nano 2007, 1, 50-56.

[31] Richard, C.; Balavoine, F.; Schultz, P.; Moreau, N.; Mioskowski, C. Immobilization of histidine-tagged proteins on functionalized carbon nanotubes. J. Bionanosci. 2007, 1, 106-113.

[32] Ali-Boucetta, H.; Al-Jamal, K. T.; McCarthy, D.; Prato, M.; Bianco, A.; Kostarelos, K. Multiwalled carbon nanotubedoxorubicin supramolecular complexes for cancer therapeutics. Chem Commun. 2008, 459-461.

[33] Liu, Z.; Fan, A. C.; Rakhra, K.; Sherlock, S.; Goodwin, A.; Chen, X.; Yang, Q.; Felsher, D. W.; Dai, H. Supramolecular stacking of doxorubicin on carbon nanotubes for in vivo cancer therapy. Angew. Chem. Int. Ed. 2009, 48, 7668-7672.

[34] Simmons, T. J.; Bult, J.; Hashim, D. P.; Linhardt, R. J.; Ajayan, P. M. Noncovalent functionalization as an alternative to oxidative acid treatment of single wall carbon nanotubes with applications for polymer composites. ACS Nano $\mathbf{2 0 0 9}$, 3, 865-870.

[35] Peigney, A.; Laurent, C.; Flahaut, E.; Bacsa, R. R.; Rousset, A. Specific surface area of carbon nanotubes and bundles of carbon nanotubes. Carbon 2001, 39, 507-514.

[36] Astronomo, R. A.; Burton, D. R. Carbohydrate vaccines: Developing sweet solutions to sticky situations? Nature Rev. Drug Discover. 2010, 9, 308-324.

[37] Dube, D. H.; Bertozzi, C. R; Glycans in cancer and inflammation-potential for therapeutics and diagnostics. Nature Rev. Drug Discover. 2005, 4, 477-488.

[38] Seeberger, P. H.; Werz, D. B. Synthesis and medical applications of oligosaccharides. Nautre 2007, 446, 10461051.

[39] Lundquist, J. J.; Toone, E. J. The cluster glycoside effect. Chem. Rev. 2002, 102, 555-578.
[40] Mammen, M.; Choi, S. K.; Whitesides, G. M. Polyvalent interactions in biological systems: Implications for design and use of multivalent ligands and inhibitors Angew. Chem. Int. Ed. 1998, 37, 2754-2794.

[41] Chen, X.; Tam, U. C.; Czlapinski, J. L.; Lee, G. S.; Rabuka, D.; Zettl, A.; Bertozzi, C. R. Interfacing carbon nanotubes with living cells. J. Am. Chem. Soc. 2006, 128, 6292-6293.

[42] Wang, H.; Gu, L.; Lin, Y.; Lu, F.; Meziani, M. J.; Luo, P. G.; Wang, W.; Cao, L.; Sun, Y. P. Unique aggregation of anthrax (bacillus anthracis) spores by sugar-coated singlewalled carbon nanotubes. J. Am. Chem. Soc. 2006, 128, 13364-13365.

[43] Khiar, N.; Pernía Leal, M.; Baati, R.; Ruhlmann, C.; Mioskowski, C.; Schultz, P.; Fernández, I. Tailoring carbon nanotube surfaces with glyconanorings: New bionanomaterials with specific lectin affinity. Chem. Commun. 2009, 27, 4121-4123.

[44] Assali, M.; Pernía Leal, M.; Fernández, I.; Baati, R.; Mioskowski, C.; Khiar, N. Non-covalent functionalization of carbon nanotubes with glycolipids: Glyconanomaterials with specific lectin-affinity. Soft Matter 2009, 5, 948-950.

[45] Andersson, C. H.; Lahmann, M.; Oscarson, S.; Grennberg, $\mathrm{H}$. Reversible non-covalent derivatisation of carbon nanotubes with glycosides. Soft Matter 2009, 5, 2713-2716.

[46] Zhang, J.; Lee, J. K.; Wu, Y.; Murray, R. W. Photoluminescence and electronic interaction of anthracene derivatives adsorbed on sidewalls of single-walled carbon nanotubes. Nano Lett. 2003, 3, 403-407.

[47] Paloniemi, H.; Ääritalo, T.; Laiho, T.; Liuke, H.; Kocharova, N.; Haapkka, K.; Terzi, F.; Seeber, R.; Lukkari, J. Water-soluble full-lenght single-wall carbon nanotube polyelectrolytes: Preparation and characterization. J. Phys. Chem. B. 2005, 109, 8634-8642.

[48] Kar, T.; Bettinger, H. F.; Scheiner, S.; Roy, A. K. Noncovalent $\pi-\pi$ stacking and $\mathrm{CH}---\pi$ interactions of aromatics on the surface of single-wall carbon nanotubes: An MP2 study. J. Phys. Chem. C. 2008, 112, 20070-20075.

[49] Brown, A. P.; Anson, F. C. Molecular anchors for the attachment of metal complexes to graphite electrode surfaces. J. Electroanal. Chem. 1977, 83, 203-206.

[50] Pérez, E. M.; Martín, N. Curves ahead: Molecular receptors for fullerenes based on concave-convex complementarity. Chem. Soc. Rev. 2008, 37, 1512-1519.

[51] Brown, A. R.; Irving, S. L.; Ramage, R. Affinity purification of synthetic peptides and proteins on porous graphitised carbon. Tetrahedron Letters. 1993, 34, 7129-7132.

[52] Brown, A. R.; Irving, S. L.; Ramage, R.; Raphy, G. (17-Tetrabenzo $[a, c, g, i]$ fluorenyl) methyl chloroformate ( TbfmocCl) a reagent for the rapid and efficient purification 
of synthetic peptides and proteins. Tetrahedron 1995, 51, 11815-11830.

[53] Ramage, R.; Wahl, F. O. 4-(17-Tetrabenzo [a,c,g,i] fluorenylmethyl)-41', 4"-dimethoxytrityl chloride: A hydrophobic 5 '-protecting group for the separation of synthetic oligonucleotides. Tetrahedron Letters 1993, 34, 7133-7136.

[54] Kolb, H. C.; Finn, M. G.; Sharpless, K. B. Click chemistry: Diverse chemical function from a few good reactions. Angew. Chem. Int. Ed. 2001, 40, 2004-2021.

[55] Tornøe, C. W.; Christensen, C.; Meldal, M. Peptidotriazoles on solid phase: [1,2,3]-Triazoles by regiospecific copper(I)catalyzed 1,3-dipolar cycloadditions of terminal alkynes to azides. J. Org. Chem. 2002, 67, 3057-3064.

[56] Hay, A. M.; Hobbs-Dewitt, S.; MacDonald, A. A.; Ramage, R. Use of tetrabenzo $[a, c, g, i]$ fluorene as an anchor group for the solid/solution phase synthesis of the quinolone antibacterial, ciprofloxacin. Synthesis 1999, 11, 1979-1985.

[57] Yang, Z.; Chen, X.; Chen, C.; Li, W.; Zhang, H.; Xu, L.; Yi, B. Noncovalent-wrapped sidewall functionalization of multiwalled carbon nanotubes with polyimide. Polymer Composites, 2007, 28, 36-41.
[58] Brown, S. D. M.; Jorio, A.; Dresselhaus, M. S.; Dresselhaus, G. Observations of the D-band feature in the raman spectra of carbon nanotubes. Phys. Rev. B. 2001, 64, 073403.

[59] Yang, Q.; Shuai, Li.; Zhou, J.; Lu, F.; Pan, X. Functionalization of multiwalled carbon nanotubes by pyrene-labeled hydroxypropyl cellulose. J. Phys. Chem. B 2008, 112, 12934-12939.

[60] D’Souza, F.; Ito, O. Supramolecular donor-acceptor hybrids of porphyrins/phthalocyanines with fullerenes/carbon nanotubes: Electron transfer, sensing, switching, and catalytic applications. Chem. Commun. 2009, 4913-4928.

[61] Banerjee, R.; Das, K.; Ravishankar, R.; Suguna, K.; Surolia, A.; Vijayan, A. M. Conformation, protein-carbohydrate interactions and a novel subunit association in the refined structure of peanut lectin-lactose complex. J. Mol. Biol. 1996, 259, 281-296.

[62] Balavoine, F.; Schultz, P.; Richard, C.; Mallouh, M.; Ebbesen, T. W.; Mioskowski, C. Helical crystallization of proteins on carbon nanotubes: A first step towards the development of new biosensors. Angew. Chem. Int. Ed. 1999, 38, 1912-1915. 